\title{
The natural and the social that we all are, the human beings: Reflections about knowledge, subjectivity, and food
}

This Thematic Section brings themes situated in the scope of discussions relating to the epistemological bases that guide the field of Food and Nutrition, more specifically, studies derived from the presentations composing the $5^{\text {th }}$ Seminar of Graduate Methods in Food and Nutrition organized by the National Forum of Coordinators of Graduate Programs in Food and Nutrition. This event took place during the $12^{\text {th }}$ National Congress of the Brazilian Society of Food and Nutrition in the city of Foz do Iguaçu, Paraná, in August 2013.

It is worth citing that this Seminar dealt with two debate fronts: the first, of biomedical nature, whose texts are published in issue number 5 of the "Journal of Nutrition" in the year, 2014; the second, corresponding to the texts presented herein and that derived from reflections evoked at the round table called "Knowledge, subjectivity, food, and nutrition: Methodological aspects." The participants of this round table integrate the only two research groups that support these research lines founded on the Humanities and Social Sciences that comprise graduate programs inserted in the assessment area called "Nutrition" in the Coordenação de Aperfeiçoamento de Pessoal de Nivel Superior, as follows: the study core about Culture and Food of the Universidade Estadual do Rio de Janeiro and the study and research core about Food and Culture of the Universidade Federal da Bahia.

This theme elected during the programming of the event denotes the scope of development of studies that are situated in this interface, therefore reflecting the interest of professionals, researchers, and students in the area of food and nutrition, and in this track, the epistemological and practical unfolding that emerges from a scientific field, if we can call it such, interstitial in growing flowering.

The set begins with an essay on issues regarding theory and method, when one considers the production of knowledge in the space where the humanities and social sciences meet the sciences of food and nutrition, having health as a common element. It involves a particular effort that brings to the fore the "need of broadening the understanding of the phenomena that surround the field of food and nutrition based on other theoretical references, to beyond the biomedical paradigm" (p.3).

The second text regards the concepts of biopower and biopolitics of Michel Foucault, bringing them to the field of food and nutrition. The authors argue that biomedicine generates a knowing-power that in turn generates discourses with regulating effects that spread out in the social facric, resulting in a strong disciplining of life. Therefore, they try to bring contributions to the reflection about the production of knowledge "that in its essence are clearly political, since they translate tensions between conceptual structures that also operate inside the field" (p.2).

The last article discusses the complexity of human life in society based on Max Weber. 
Thinking about the discourses generated in the scope of the biomedical norms on eating and physical activity, as well as food and body practices in daily life, its authors propose a theoreticalinstrumental tool for scientific research called décalage. Through this means they aim to favor the understanding of the agents that act in the field of food and nutrition and physical education - and by extension - of health - in its contradictions/consensus/conflicts between what is recommended and what is practiced, between what is said and what is done.

Finally, these are efforts that try to bring light to this desirable encounter between scientific fields that deal with nutrients and food, with the natural and the social. This is what we all are, the Human Beings.

Shirley Donizete PRADO ${ }^{1,2}$ Kenia Mara Baiocchi de CARVALHO 1,3

Ligia AMPARO-SANTOS 1,4

1 Coordenação do Fórum Nacional de Coordenadores de Programas de Pós-Graduação em Alimentação e Nutrição. Rio de Janeiro, RJ, Brasil.

2 Universidade do Estado do Rio de Janeiro, Instituto de Nutrição, Programa de Pós-Graduação em Alimentação, Nutrição e Saúde. Rio de Janeiro, RJ, Brasil. Correspondência para/Correspondence to: SD PRADO. E-mail: <shirley.prado@yahoo.com.br>.

3 Universidade de Brasília, Programa de Pós-Graduação em Nutrição Humana. Brasília, DF, Brasil.

${ }^{4}$ Universidade Federal da Bahia, Escola de Nutrição, Programa de Pós-Graduação em Alimentos, Nutrição e Saúde. Salvador, BA, Brasil. 